Northwestern University School of Law Northwestern University School of Law Scholarly Commons

Faculty Working Papers

2010

\title{
Competition Policy and Financial Distress
}

Ezra Friedman

Northwestern University School of Law, ezra-friedman@law.northwestern.edu

Marco Ottaviani Ottaviani

\section{Repository Citation}

Friedman, Ezra and Ottaviani, Marco Ottaviani, "Competition Policy and Financial Distress" (2010). Faculty Working Papers. Paper 36. http://scholarlycommons.law.northwestern.edu/facultyworkingpapers/36 


\title{
Competition Policy and Financial Distress*
}

\author{
Ezra Friedman ${ }^{\dagger} \quad$ Marco Ottaviani ${ }^{\ddagger}$
}

January 2010

\begin{abstract}
Traditional analyses of competition policy assume that firms operate in perfect credit markets. We argue that imperfections in credit markets should be taken into account, and show one channel by which accounting for financial conditions could alter the welfare effects of a merger. In line with empirical evidence, we posit that the presence of financial distress might diminish price competition by reducing firms' willingness to undertake long-term investments in their customer base. Mergers that reduce the probability of financial distress can induce the merging firms to compete more fiercely for customers, thus partly offsetting the traditional effects of an increase in market power. We use this framework to derive implications for competition policy.
\end{abstract}

${ }^{*}$ We are grateful for comments by Jonathan Baker (our discussant) and the other participants of the Second Annual Research Symposium on Antitrust Economics and Competition Policy at at Northwestern University School of Law.

${ }^{\dagger}$ Northwestern University School of Law, 357 East Chicago Avenue, Chicago, IL 60611, USA. Email: ezra.friedman@me.com.

${ }^{\ddagger}$ Kellogg School of Management, Northwestern University, 2001 Sheridan Road, Evanston, IL 60208-2013, USA. Email: m-ottaviani@northwestern.edu. 


\section{Introduction}

The recent financial crisis has brought to the fore of the debate the question whether competition policy should take financial factors into account. By and large, the current practice (as well as the theory) of competition policy abstracts from the financial side, and is mostly predicated on the simplifying view that firms have access to perfect capital markets. For instance, economists traditionally frame the social desirability of mergers in terms of Williamson's (1968) tradeoff between efficiency gains and loss of competition resulting from the merger. In this paper, we explore how this tradeoff for policy makers is affected by considerations related to the financial status of the merging firms.

Much of the extant literature on how financial health should affect competition policy focuses on the failing firm defense and is based on considerations about the $e x$ post consequences of firm failure on future market structure and consumer welfare. ${ }^{1}$ In contrast, the effects we are concerned with operate on firm strategy through the $e x$ ante incentives of the fear of financial failure. In this paper we focus on one particular channel through which financial factors affect the competitive impact of a merger. ${ }^{2}$ In our model, firms face some risk of insolvency, and a merger tends to mitigate that risk. In order to isolate the ex ante channel, we initially focus on a model in which all of the competition for customers occurs before any failure. We show that the reduced likelihood of insolvency might induce a firm to compete more aggressively, and can reverse the traditional competitive effects of a merger.

The specific model we consider is one in which consumers have switching costs, and thus firms face a tradeoff between current cash flow and future profits. Because customers are reluctant to switch suppliers, each firm may be able to increase its current cash flow by raising its current prices at the cost of future sales and profits. In this context, we introduce financial imperfections by allowing the firms to be subject

\footnotetext{
${ }^{1}$ We refer to McFarland and Nelson (2008) for an up-to-date legal account of the main issues.

${ }^{2}$ As discussed in Section 2, financial factors affect product market competition in a number of ways. Notably, financial factors can affect a firm's attitude towards risk and its effective discount rate. In turn, the firm's risk attitude and discount rate affect competitive conduct. A merger is likely to directly and indirectly alter the financial constraints faced by firms
} 
to the possibility of financial distress and bankruptcy.

The presence of financial distress motivates firms to maximize short-term profits for two reasons. First, the possibility that a firm might fail increases the effective discount rate on future earnings from that firm. Second, the possibility that increased current profits might actually forestall liquidation increases the value of profits in the current period, again increasing the effective discount rate. Because firms in financial distress discount their future profits, they have an incentive to increase current cash flow by raising their prices. We show that the firm treats future profits it expects from a new customer in the same way it treats cost reductions in the firm's maximization function. A merger that makes it less likely that the firm will fail due to insufficient cash flow increases the relative value of these future profits, and this functions like an efficiency.

We show how to estimate the magnitude of this "financial efficiency" as a function of how much profit current customers are expected to bring the firm in the future and the relative increase in the survival probability of the firm. We show that if regulators wish to prevent any merger that raises prices they may treat this "financial efficiency" just like a technological efficiency from a merger. However, in contrast to Farrell and Shapiro (1990), who find that when there are technological synergies a price decrease post merger is a sufficient, but not necessary condition for a merger to be welfare improving, we find that when the merger creates purely financial efficiencies, a price decrease is both necessary and sufficient.

For the sake of concreteness, we focus our analysis to the case in which switching costs are sufficiently high to preclude any consumer from switching in the second period. However, the logic of the model should apply to any situation where a customer base or market share has substantial value to the firm. Our results apply to industries in which firms view a customer base to be a core asset that they can draw down by raising prices, increasing current revenue at the cost of future market share and profits. On the other hand, there might be some industries, particularly durable goods where the effects we describe would have the opposite effect. If current sales reduce future demand and future profit, financial distress removes a disciplining force 
and makes sales in the current period more attractive, thus inducing firms to compete more aggressively. ${ }^{3}$ In either case, we believe that competition policy makers may wish to consider the incentive effects of financial distress when considering proposed mergers.

\section{Literature}

Since Brander and Lewis (1986), a sizable theoretical literature has investigated the effects of a firm's capital structure on competitive conduct. Focusing on Cournot (quantity) competition, they show that a firm's incentives to produce increases in its level of debt. Intuitively, because the firm is the residual claimant for high returns, but debt holders are the residual claimants for low returns, debt makes the firm's payoff convex in the returns. Given that an increase in quantity increases the riskiness of returns, debt effectively commits the firm to produce a higher quantity for any quantity expected by the competitors. In turn, rivals respond by reducing their quantities (strategic substitutes), to the benefit of the firm. As shown by Showalter (1995), debt is also a desirable commitment when firms compete à la Bertrand (prices), provided the uncertainty is on the demand side. In this case, an increase in debt induces the firm to weigh high-demand states more because of the limited liability effect, and in those states higher prices are optimal. In turn, rivals respond by also raising their prices (strategic complements).

Building on Klemperer (1987) and (1995), Chevalier and Scharfstein (1996) model competition with switching costs in the presence of capital market imperfections. ${ }^{4}$ They note that in industries with switching costs, firms which face no risk of liquidation have incentives to raise prices during booms, and lower prices during busts, but that firms which are externally financed may have incentives to increase prices when their survival is in doubt. Our analysis builds on a similar model, but focuses on the price effect of mergers, thus extending Werden (1996) to a setting in which

\footnotetext{
${ }^{3}$ For example, Busse (2002) presents evidence that airlines cut prices so as to temporarily increase sales and cash flow in response to liquidity crises

${ }^{4}$ See also Gottfries (1991).
} 
the merger generates a financial synergy, corresponding to a reduction in the probability of financial distress. Thus, we contribute an analysis of how competition policy should take into account financial constraints.

Chevalier and Scharfstein (1996) also present empirical evidence that supermarket chains that are externally financed do indeed increase their prices during busts, when the chains are more likely to be in financial distress. Asplund, Eriksson, and Strand (2005) offer additional evidence consistent with the role played by switching costs for the intensity of price competition.

In the banking literature, Perotti and Suarez (2002) study how competition policy affects banks' incentives to undertake speculative lending, which increase short-run profits at the cost of increasing the probability of failure. They show that banks' speculative lending decisions are strategic substitutes when a lenient merger control policy allows a surviving bank to merge with a failing competitor and thereby obtain (temporary) monopoly profits. Intuitively, prudent lending is then optimal in reply to speculative lending by the competitor. In our model, instead, merger policy affects ex ante competitive structure, rather than speculative lending. In addition, we abstract from the ex post benefits from increased market power that firms might derive following a merger.

\section{Model}

Suppose we have $N$ firms competing in an industry with switching costs. In the first period potential customers choose between purchasing from any one of the $N$ firms, or not purchasing at all. We suppose that firms face a linear demand function given by $x_{i 1}=a-b p_{i 1}+\sum_{j \neq i} \gamma p_{j 1}$. We note that the diversion ratio (equal to the fraction of lost sales of one firm that are captured by a second firm following an increase in the price by the first firm) between any two firms is $\gamma / b$, and that the total inside diversion ratio is $\gamma(N-1) / b$.

In the second period, consumers face switching costs that are sufficiently large so they do not consider switching firms during that period. They buy from their current 
firm if the price is less than $R$, and otherwise leave the market. For the purposes of simplicity we assume that firms face no new customers in the second period, thus sales in the second period are given by

$$
x_{i 2}=\left\{\begin{array}{cc}
x_{i 1} & p \leq R \\
0 & p>R
\end{array}\right.
$$

Given this structure, firms in the second period will all charge $R$, so profits in the second period are $x_{i 1}\left(R-c_{i}\right)$. The total profit for firm $i$ is thus given by

$$
\Pi_{i}=\pi_{i 1}+\pi_{i 2}=\left(a-b p_{i 1}+\sum_{j \neq i} \gamma p_{j 1}\right)\left(p_{i 1}-c+R-c\right) .
$$

Given this expression, the first order condition for the first period price is

$$
b\left(p_{i 1}-c+(R-c)\right)=a-p_{i 1}+\sum_{j \neq i} \gamma p_{j 1} .
$$

Solving for $p_{i 1}$ we have

$$
p_{i 1}=\frac{a+\sum_{j \neq i} \gamma p_{j 1}+b(c-(R-c))}{2 b} .
$$

We note here that the future profit from a new customer $(R-c)$ enters into the pricing function just like a reduction in cost. Solving for the equilibrium, we immediately obtain

$$
p_{i 1}=\frac{a+b(c-(R-c))}{2 b-(N-1) \gamma}
$$

\section{Exogenous Distress}

In this section we model how firms' pricing decisions are affected by presence of financial distress, as captured by the probability that the firm does not survive into the second period. We suppose that firm $i$ is in some distress in period 1, and imagine that there is only probability $\phi_{i}$ that $i$ will survive into period 2. Following Chevalier and Scharfstein (1996) and Bolton and Scharfstein (1990) we assume that if the firm fails it does so because the firm is unable to make a scheduled fixed debt payment, and that anticipating this failure, the firm's managers are able to expropriate the first 
period's profits. At first we assume that the forces that determine whether or not the firm survives are entirely beyond its control, so the likelihood of survival does not depend on its sales in either period. When we say the firm does not survive, we do not necessarily mean that the firm liquidates, what our analysis requires is that if the firm does not survive (goes bankrupt), the first period decision makers do not see any value from the firm's future profits. This uncertainty about survival has the effect of causing the firm to discount the future profits from new customers.

Proposition 1 Holding all else equal, the firm's price is increasing in the degree of financial distress (i.e. the price is decreasing in the probability of survival)

Proof: Due to the fact that the manager only realizes period 2 profits if the firm survives, the firm is now maximizing

$$
\Pi_{i}=\pi_{i 1}+\phi_{i} \pi_{i 2}=\left(a-b p_{i 1}+\sum_{j \neq i} \gamma p_{j 1}\right)\left(p_{i 1}-c+\phi_{i}(R-c)\right) .
$$

The new first order condition, solved for price is

$$
p_{i 1}=\frac{a+\sum_{j \neq i} \gamma p_{j 1}+b\left(c-\phi_{i}(R-c)\right)}{2 b} .
$$

QED

We see that holding all else constant, the effect of decreasing the survival probability, $\phi_{i}$, is to increase the price. The intuition is that the future marginal profits from of an additional customer, $R-c$, could be seen as equivalent to a cost decrease in selling to this customer. Diminishing the likelihood of firm survival diminishes the likelihood of realizing this cost decrease, leading to a price increase.

\subsection{Effect of Merger}

Suppose that there is a proposed merger between firm $i$ and firm $j$, and this merger would be completed prior to sales in period 1. Suppose also that the merger does not lead to any technological efficiencies or changes in available products. If not for the issue of financial distress, the effect of the merger would be to increase prices for 
both products, because each division of the merged firm would no longer consider sales diverted to the other division as lost sales. However here we show that, if the merger partially alleviates the financial distress, the merger can actually lead to a price decrease. For the sake of simplicity we will assume that prior to the merger both firms $i$ and $j$ had the same likelihood of survival and that due to the merger the likelihood of survival increases from $\phi_{i}$ to $\phi_{M}$.

The merger could increase the likelihood of survival for several reasons. Firstly, the risks that the merging firms face may not be perfectly correlated, so a merger might lessen the risk of failure due to a risk pooling effect. Each firm may not be strong enough to survive a bad outcome on its own, but a merged firm may be strong enough to survive as long as both firms do not receive this bad outcome. Similarly, a firm that relies on short term financing is likely to have relationships with only a few banks, if all of those banks are impacted by a systemic liquidity crises, none of the banks may be willing to roll over any of their loans. The acquiring firm may very well have relationships with some different banks who might not be suffering from the crisis to the same degree, and thus might be willing to roll over the target firms loans.

Secondly, the future prospects of the merged firm are likely to be brighter, thus the merged firm may be seen as more creditworthy and face a softer liquidity constraint. Finally the merger may involve a well capitalized firm merging with a poorly capitalized rival, and the acquiring firm may be sufficiently well capitalized to face little risk of failure. ${ }^{5}$

In the second period, the merged firm will continue to charge $R$, for both goods because there are no new customers, and the diversion ratio for old customers is 0 , since old customers buy from their old firm or leave the market. However, the merger will likely lead to a change in price in the first period. To introduce our result, we

\footnotetext{
${ }^{5}$ This last scenario does not precisely fit the model, because we have assumed for the sake of simplicity that the merging firms are identical. If we have a well-capitalized firm merging with a firm in financial distress, the merger might lead the well-capitalized firm to increase prices, while the poorly-capitalized firm lowers prices. The approach developed in this paper could nonetheless be used to predict the effect of the merger on average prices and welfare.
} 
define $d=\frac{\gamma}{b}$ as the diversion ratio between the merging firms, and $\Psi=\frac{p_{i 1}-c+\phi_{i}(R-c)}{\phi_{i}(R-c)}$ as the ratio between total expected profit from a new customer and the portion that is expected to be realized in the second period. Note that $\Psi$ will be greater than one as long as $p_{i 1}>c$, but if $p_{i 1}<c$, that is to say if firms find it profitable to subsidize purchases in the first period in order to reap higher profits in the second, then $\Psi$ will be lower than 1 .

Whether we expect a price increase or decrease from the merger depends upon the change in survival probability, the diversion ratio, and the fraction of profit per customer that is realized in the second period. Specifically we have:

Proposition 2 The merger will lead to a decrease in prices if and only if $\frac{\phi_{M}-\phi_{i}}{\phi_{i}}>$ $\frac{d}{1-d} \Psi$

Proof: Let us use $\delta$ to refer to the difference in the second period price between the merged and unmerged scenarios.

In the first period, the new first order condition is

$$
b\left(p_{i 1}-c+\phi_{M}(R-c)\right)-\gamma\left(p_{j 1}-c+\phi_{M}(R-c)\right)=a+\sum_{k \neq i} \gamma p_{k 1}-b\left(p_{i 1}\right),
$$

so that

$$
p_{i 1}=\frac{a+\sum_{k \neq i} \gamma p_{k 1}+\gamma\left(p_{j 1}-c+\phi_{M}(R-c)+b\left(c-\phi_{M}(R-c)\right)\right.}{2 b} .
$$

The change in price is given by

$$
\delta_{i}=\frac{\sum_{k \neq i} \gamma \delta_{k 1}+\gamma\left(p_{j 1}-c+\phi_{M}(R-c)\right)}{2 b}-\frac{\phi_{M}-\phi_{i}}{2}(R-c) .
$$

By symmetry, we know the firm will charge the same for goods $i$ and $j$, and a necessary and sufficient condition for $\delta_{i}$ to be positive is

$$
\partial p_{i}=\frac{\gamma\left(p_{j 1}-c+\phi_{i}(R-c)\right)}{2 b}-\frac{(b-\gamma)\left(\phi_{M}-\phi_{i}\right)}{2 b}(R-c)>0 .
$$

Our condition for a price increase due to merger can be written as

$$
\frac{\phi_{M}-\phi_{i}}{\phi_{i}}<\frac{d}{1-d} \Psi
$$


We note that in this linear demand system, the actions of the competitors are strategic complements, so if the merged firm is charging lower prices for its goods, all of the competitors will charge lower prices as well. There are two opposing effects from the merger. First, there is the standard competitive effect of the merger, the fact that the firm faces a lower effective elasticity since some of the customers who choose not to buy product $i$ choose to buy product $j$ instead. The second effect is the fact that new customers have more value to the merged firm because the merged firm is more likely to survive, $\phi_{M}>\phi_{i}$. Because these new customers have more value to the merged firm, the merged firm competes more vigorously to obtain customers in the first period.

As expected, increasing the diversion ratio implies that it is more likely that the merger will lead to a price increase. Decreasing $\Psi$, and increasing the relative importance of future profits makes the increase in survival probability more important, and thus makes it more likely that the merger will lead to a price decrease. Likewise, increasing $\phi_{M}$, or decreasing $\phi_{i}$, increases the survival effect of the merger, and makes a price decrease more likely.

\subsection{Welfare Effects}

In their seminal work on the welfare effect of a merger Farrell and Shapiro examine mergers between firms that compete in a Cournot equilibrium, and show that an increase in output (and a decrease in price) is a sufficient condition for an increase in welfare. In contrast, in our model a decrease in prices is a necessary and sufficient condition for an increase in welfare in the first period. The difference is that the efficiencies in the type of merger examined by Farrell and Shapiro reduce the social cost of producing the good. If output is decreased slightly (and prices are slightly increased), this indicates a decrease in consumer surplus. However, it is still possible that reduced social cost from production outweighs the decrease in consumer surplus, and the merger increases welfare. In the model examined in the paper the efficiency 
from the increased likelihood of survival is not a production efficiency, it does not actually reduce the social costs of production. Rather it is an allocative efficiency as it comes from more closely aligning the incentives of the firm with social efficiency. In essence, because of the merger, the management of the firm is able to capture a greater fraction of the future surplus from each captured customer, and thus its incentives are more closely aligned with society. However, the merger also increases the market power of the firm, increasing the incentive to raise price, leading to more deadweight loss. Since these two effects both operate purely on the pricing decision of the firm, whether the merger increases or decreases social welfare depends purely on whether the merged firm's price moves closer to or farther from the social cost. We start by noting that consumer surplus $S$ is a decreasing function of the price vector $p$, and $S_{i}(p) \equiv \partial S / \partial p_{i}=-x_{i 1}$. The total producers' profit is just $\sum_{i \leq N} \pi_{i}=$ $\sum_{i \leq N} x_{i 1}(p+R-2 c)$. Recall that we are assuming that if a firm fails, its productive assets are purchased prior to the next period, and that the purchaser of its assets will supply to the captive customer base, so there are no real effects from failure. Although failure may affect who (i.e. debt or equity) receives the profits in the second period, total enterprise profits are not affected. Without loss of generality, let $j$ and $k$ represent the firms that are merging. Suppose that the merger leads to a price decrease so $p_{M}<p_{j}$.

The marginal change in social welfare from a price increase for good $j$ is

$$
\frac{d W}{d p_{j}}=-x_{j}+\left(x_{j}-b\left(p_{j}+R-2 c\right)\right)+\sum_{i \neq j, k} \frac{d p_{i}}{d p_{j}}\left(-x_{i}+\left(x_{i}-b\left(p_{i}+R-2 c\right)\right)\right.
$$

Note that $\left(p_{j}+R-2 c\right)>0$, and $\left(p_{i}+R-2 c\right)>0$, otherwise the firms would not be profitable, similarly, we recall that $d p_{i} / d p_{j}>0$. Thus $d W / d p_{j}<0$. The same result also holds for $d W / d p_{k}$. We conclude that any merger which decreases prices for the merging firms would increase welfare, and any merger which increases prices would decrease welfare. 


\section{$5 \quad$ Endogenous Distress}

In the previous section, we assumed that the probability of survival was not affected by the pricing decisions of the firm. In this section we allow for the possibility that the probability of survival depend upon how much cash on hand the firm has at the end of the first period, and the firm may take this into account. Specifically, we imagine that the firm faces a stochastic cash requirement to survive into the second period. The firm relies on callable short term financing, and that due to forces beyond control of the firm, at the end of period some banks call in a portion of their loans. Let $z$ be the amount of short term debt called by the banks, we assume that if the firm cannot pay back the called loans it fails, so the firm needs to have at least $z$ available as cash in order to continue to operate in the second period. We imagine that $z$ is not known in advance, rather it is a random variable distributed according to the cumulative distribution function $G$, so $G(z)$ represents the likelihood that the amount of cash demanded will be equal to or less than $z$. We assume that the distressed firm has no available cash prior to the start of the first period, so the firm's survival is dependent upon the first period profits exceeding the cash needed to operate. The firm survives if $\pi_{i 1}>z$, so the likelihood of survival is $G\left(\pi_{i 1}\right)$. If the firm lacks the cash necessary to operate, it enters bankruptcy and is either liquidated or reorganized. ${ }^{6}$

Suppose the total debt of the firm is $L$, and assume that $L<\pi_{i 2}$, so the manager of the firm would never prefer to expropriate the available cash at the end of the first period if there is enough to pay off the fraction of the loan that is called. If the firm is able to pay $z$ at the end of the first period, it will be able to pay $L-z$ in the second period, and pay off its debts entirely. Thus if the firm fails, the manager's payoff is $\pi_{i 1}$, and if it succeeds the payoff is $\pi_{i 1}+\pi_{i 2}-L$, so the firm wishes to maximize $\pi_{i 1}+G\left(\pi_{i 1}\right)\left(\pi_{i 2}-L\right)$.

Proposition 3 Holding all else equal, the firm's price is increasing in the degree of financial distress, and also increasing in the sensitivity of survival to profits, $g\left(\pi_{i 1}\right)$.

\footnotetext{
${ }^{6}$ In this simple model our results do not depend upon what happens to the firm when it cannot make payments, it is only necessary to assume that conditional on bankruptcy, future profits are of no value to the pre-bankruptcy decision makers.
} 
Proof: The first order condition for $p_{i 1}$ is

$$
\frac{d \pi_{i 1}}{d p_{i 1}}+g\left(\pi_{i 1}\right) \frac{d \pi_{i 1}}{d p_{i 1}}\left(\pi_{i 2}-L\right)+G\left(\pi_{i 1}\right) \frac{d \pi_{i 2}}{d p_{i 1}}=0 .
$$

For the sake of brevity, we use $\zeta$ to refer to the ratio between the weight of the second period profit and first period profit in a firm's maximization problem. Thus $\zeta_{i}=$

$\frac{G\left(\pi_{i 1}\right)}{1+g\left(\pi_{i 1}\right)\left(\pi_{i 2}-L_{i}\right)}$. Plugging in our linear demand equations, our first order condition becomes

$$
\left(x_{i 1}-b\left(p_{i 1}-c_{i}\right)\right)+b \zeta_{i}(R-c)=0 .
$$

Solving for price, we have

$$
p_{i 1}=\frac{a+\gamma \sum_{j \neq i} p_{j 1}+b\left(c-\zeta_{i}(R-c)\right)}{2 b} .
$$

We note that price is decreasing in $\zeta_{i}$ and $\zeta_{i}$ is increasing in the probability of survival, $G\left(\pi_{i 1}\right)$, so it is decreasing in financial distress. We note also that $\zeta_{i}$ is decreasing in the sensitivity of survival to profits, $g\left(\pi_{i 1}\right)$.

QED

To compare this to our expression for pricing with exogenous distress, we first note that $G\left(\pi_{i 1}\right)$ is the probability of survival, so it is the analog of $\phi_{i}$ in the exogenous failure model. Looking at our expression for $\zeta_{i}$, we see that $\zeta_{i}<G\left(\pi_{i 1}\right)$, implying that compared to a firm facing the same probability of exogenous failure, a firm facing endogenous failure will discount the future more, charging higher prices because it values future profits less. When survival into the future is dependent upon current cash flow, this gives an additional reason for the firm to focus on current cash flow as opposed to future profitability. The firm both discounts future profits by the likelihood they are never realized, and places more value on current cash flow as a means of realizing that future profit.

\subsection{Effects of Merger under Endogeneity}

Considering the endogeneity of firm survival can make it more likely that a merger reduces prices in the first period, particularly when the merger makes the probability 
of failure insensitive to future increases in profit by reducing any substantial likelihood of firm failure. We suppose there is a post merger survival function $G_{M}$, so that after the merger, the probability of survival is given by $G_{M}\left(\pi_{M 1}\right)$. Analogously to our definition of $\zeta_{i}$, we define $\zeta_{M}=\frac{G_{M}\left(\pi_{M 1}\right)}{1+g_{m}\left(\pi_{M 1}\right)\left(\pi_{M 2}-L_{M}\right)}$.

Our new test for a price increase from the merger is given by the following proposition:

Proposition 4 The merger will lead to a price increase if and only if

$$
\frac{\zeta_{M}-\zeta_{i}}{\zeta_{i}}<\frac{d}{1-d} \frac{p_{i 1}-c+\zeta_{i}(R-c)}{\zeta_{i}(R-c)}
$$

This expression is similar to expression (4), but the last term $\frac{p_{i 1}-c+\zeta_{i}(R-c)}{\zeta_{i}(R-c)}$ is now the ratio of total profits to expected future profits, with both terms being discounted by the firm's effective discount rate, (which considers both the fact that the firm might not survive, and the fact that period 1 cash flow might influence that survival). The new expression for $\delta$ is

$$
\delta_{i}=\frac{\sum_{k \neq i} \gamma \delta_{k}+\gamma\left(p_{j 1}-c-\zeta_{M}(R-c)\right)}{2 b}-\frac{\zeta_{M}-\zeta_{i}}{2}(R-c) .
$$

In general, whether considering the endogeneity of the firm's survival increases or decreases the likelihood that the merger leads to a price increase is ambiguous. If we place no restrictions on the shape of the survival functions $G_{i}$ and $G_{M}$, it is easy to construct parameters where a merger increases the likelihood of survival yet leads to a negative financial inefficiency. Specifically, suppose that absent the merger the firm is likely to survive only if a discrete exogenous event such as a regulatory change occurs, but that the merger strengthens the combined firm enough so that it just might survive absent that change if it is able to substantially increase its short term profits. Thus the merger shifts the firm into a more sensitive region of the survival function, so that $g_{M}\left(\pi_{M 1}\right) \pi_{M 2}>g_{i}\left(\pi_{i 1}\right)\left(\pi_{i 1}+\pi_{i 2}-L_{i}\right)$. See Figure 1a. As long as absolute likelihood of survival is not increased too much it can be the case that $\frac{G_{M}(R-c)}{1+g_{M}\left(\pi_{M 1}\right)\left(\pi_{M 1}+\pi_{M 2}-L_{M}\right)}<G_{i}(R-c) 1+g_{i}\left(\pi_{i 1}\right)\left(\pi_{i 1}+\pi_{i 2}-L_{i}\right)$, implying that the merged firm places more emphasis on short term profits than the unmerged firm, and 

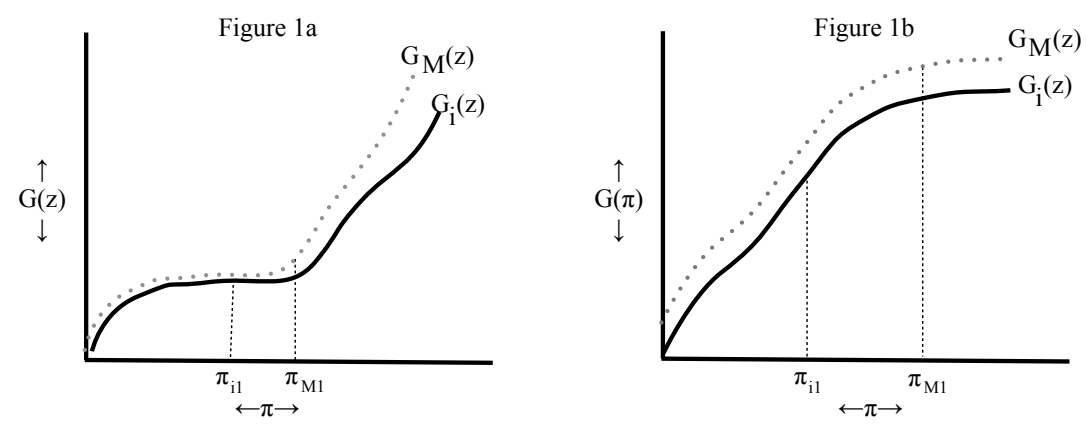

Figure 1: Probability of survival as a function of first period cash flow. Dotted lines represent the survival function for the merged firm. Note that $g(z)$ is the slope of $G(z)$ 
the price increase from the merger will actually be greater than that expected merely from the loss of competition.

More broadly, if the merger does not substantially decrease the sensitivity of survival to profit, making survival endogenous decreases the impact from the financial efficiency from merger. If the increase in survival probability from a proportionate increase in cash flow is roughly the same pre and post merger, ${ }^{7}$ so that $g_{i}\left(\pi_{i 1}\right)\left(\pi_{i 1}+\right.$ $\left.\pi_{i 2}-L_{i}\right) \approx g_{M}\left(\pi_{M 1}\right)\left(\pi_{M 1}+\pi_{M 2}-L_{M}\right)$, both pre and post merger firms discount the future by approximately the same additional factor of $1+g_{M}\left(\pi_{M 1}\right)\left(p i_{M 1}+\pi_{M 2}-L_{M}\right)$, and the magnitude of the financial efficiency due to the reduced probability of failure is decreased by this factor as well.

In any case, considering the endogeneity of survival increases the maximum possible magnitude of the 'financial efficiency', which occurs when the merger removes any possibility of failure. In this case, $G_{M}\left(\pi_{M 1}\right)=1$ and $g_{M}\left(\pi_{M 1}\right)=0$, so the magnitude of the efficiency would be $\left(1-\frac{G\left(\pi_{i 1}\right)}{\left(1+g\left(\pi_{i 1}\right) \pi_{i 2}\right)}\right)(R-c)$, which is clearly greater than the maximum efficiency with exogenous mergers, which is $\left(1-G\left(\pi_{i 1}\right)\right)(R-c)$. Speaking generally, if the merger removes the firm from the region where survival is sensitive to profit, (as in Figure 1b) considering the endogeneity is likely to increase the financial efficiency due to mergers, as stated in the following proposition:

Proposition 5 Compare two mergers, one in a scenario where failure is exogenous (firms $i$ and $j$ ), one where failure is endogenous (firm $u$ and $v$ ), but both between firms with the same likelihood of failure, i.e. $\phi_{i}=G\left(\pi_{u 1}\right)$. If all else is held constant, the merger in the scenario where failure is endogenous is more likely to reduce prices.

\footnotetext{
${ }^{7}$ After the merger, the lost profits from firm failure tend to be substantially greater, so that if the absolute sensitivity of survival to profit $(g(\pi))$ is not decreased, the emphasis on current profit is higher, because the stakes from survival are higher and the firm wants to guarantee its survival. On the other hand, the merged firm is presumably of a larger scale. so one might expect that the same absolute increase in profit might have less absolute effect on firm survival.
} 


\section{Robustness}

\subsection{Demand Specification}

We have chosen a specific, simple demand function for our analysis, and one might ask how this affects the robustness of our results. Although the magnitude of a merger typically depends strongly on the shape of a demand function, as pointed out by Werden (1996), the sign of the price effect from a merger is typically determined by a comparison between the margin, the magnitude of the efficiency, and the diversion ratio.

Following Werden's (1986) intuition, we can show that our results are robust to any symmetrical demand system.

Proposition 6 In any symmetrical equilibrium of a symmetrical demand system, the merging firm will find a price increase profitable if and only if $\frac{\zeta_{M}-\zeta_{i}}{\zeta_{i}}<\frac{d}{(1-d)} \frac{p_{i 1}-c+\zeta_{i}(R-c)}{\zeta_{i}(R-c)}$.

Proof: Consider a symmetrical model where demand is given by a function $x_{i 1}\left(\mathbf{p}_{1}\right)$ where $\mathbf{p}_{1}$ is the vector of first period prices and $\zeta_{i}$ is the relative weight of the second period profits compared to first in firm $i^{\prime} s$ optimization. The first order condition pre-merger is

$$
x_{i 1}+\frac{d x_{i 1}}{d p_{i 1}}\left(p_{i 1}-c\right)+\zeta_{i}(R-c)=0 .
$$

Consider a merger between $i$ and $j$ that increases the likelihood of survival, or diminishes the sensitivity of survival to cash flow so $\zeta_{M}>\zeta_{i}$. Holding other prices constant, the increment to expected profit from a first period price increase is now given by

$$
\left.\left.\frac{d \Pi_{i}}{d p_{i 1}}=x_{i 1}+\frac{d x_{i 1}}{d p_{i 1}}\left(p_{i 1}-c\right)+\zeta_{M}(R-c)\right)+\frac{d x_{j 1}}{d p_{i 1}}\left(p_{j 1}-c\right)+\zeta_{M}(R-c)\right) .
$$

We note that $\frac{\frac{d x_{j 1}}{d p_{i 1}}}{\frac{d x_{i 1}}{d p_{i 1}}}=-d$, and by symmetry $p_{j 1}=p_{i 1}$ so that we have

$$
\frac{d \Pi_{i}}{d p_{i 1}}=\frac{d x_{i 1}}{d p_{i 1}}\left(\left(\zeta_{M}-\zeta_{i}\right)(R-c)-d\left(\zeta_{M}-\zeta_{i}\right)(R-c)-d\left(\left(p_{i 1}-c+\zeta_{i}(R-c)\right)\right) .\right.
$$


Given that $\frac{d x_{i 1}}{d p_{i 1}}$ is negative, we have

$$
\frac{d \Pi_{i}}{d p_{i 1}}>0 \Leftrightarrow \frac{\zeta_{M}-\zeta_{i}}{\zeta_{i}}<\frac{d}{(1-d)} \frac{p_{i 1}-c+\zeta_{i}(R-c)}{\zeta_{i}(R-c)} .
$$

QED

\subsection{Ability to Borrow Against Future Earnings}

Our result that making the firm survival endogenous increases the degree to which the firms discount the future is predicated on the assumption that the firm's survival depended only on cash in hand and that it had no ability to finance operations by borrowing against future earnings. Admittedly, the prospects for future profits might also enter into the firm's credit-worthiness and hence its survival. However, because future profits are inherently uncertain, and any claim on future profits by a creditor likely introduces moral hazard problems or other constraints on the operation of the firm, we would expect that an expectation of future profits cannot be fully monetized, and that a bird in the hand is worth somewhat less than a bird in the bush. Given our concern with financial crises in this paper, we might expect that expectations of future earnings are particularly hard to borrow against in times of an economy-wide liquidity crisis.

We might model the effect of expected future profits on firm survival by supposing that the likelihood of survival is now $G\left(\pi_{i 1}+\lambda \pi_{i 2}\right)$, where $\lambda<1$ is the degree to which future profits can be borrowed against. The first order condition is now

$$
p_{i 1}=\frac{a+\gamma \sum_{j \neq i} p_{j 1}+b\left(c-\frac{G\left(\pi_{i 1}+\lambda \pi_{i 2}\right)\left(1+\lambda g\left(\pi_{i 1}+\lambda \pi_{i 2}\right)\left(\pi_{i 1}+\pi_{i 2}-L\right)(R-c)\right)}{1+g\left(\pi_{i 1}\right)\left(\pi_{i 1}+\pi_{i 2}-L\right)}(R-c)\right)}{2 b} .
$$

Comparing this expression to the prices with exogenous distress (2) and with the hard cash on hand constraint (6) we note that although a loose cash in hand constraint $(\lambda>0)$, causes the firm to discount the future less than a hard cash in hand constraint, as long as future profits are not considered the equivalent of cash on hand $(\lambda<1)$, the firm will discount the future more when survival is made endogenous. Thus the results regarding the exogenous failure can be seen as a lower bound on the degree to which financial distress causes the firm to discount the future. 


\subsection{Ability to Expropriate}

The assumption that the managers of the firm can expropriate all of the cash flow when the firm is unable to make the payment may appear to be somewhat extreme. However, as long as managers of the firm are able to obtain some benefits from firstperiod profits prior to bankruptcy, the qualitative results will be the same, although the magnitude of the effect would be lower. As shown by Dasgupta and Titman (1998), even when managers are effectively barred by covenants from removing any earnings from the corporation, they may act as if they can. ${ }^{8}$ The empirical results of Chevalier and Scharfstein (1996) lend support to the hypothesis that companies that are in distress increase prices because they place less weight on potential future earnings.

\section{Extension: Future Competition}

With the model we have been considering, analyzing consumer welfare analysis is relatively simple. In the second period, there are no new consumers, and all old consumers pay $R$, their reservation price. Thus, old consumers receive no surplus in the second period, regardless of what happens in the first period, so consumer welfare is purely dependent on what occurs in the first period. However, this simple analysis is dependent on the assumption that no new customers enter the market after the first period, and that old customers are completely indifferent to the prices being charged by other firms. Because firms do not need to worry about new customers in the second period, and old customers are captive, the firms' behavior in the first period does not depend on their expectations of competition in the second period.

In this section, we discuss how these results might change in a more complete model that allowed for competition in the second period. If new customers arrived in the second period, and the firms were constrained to charge the same to new and old customers, then expectations of future competitions would affect the firms' behavior

\footnotetext{
${ }^{8}$ The intuition behind Dasgupta and Titman's (1998) result is that management can essentially reduce the priority of senior debt by using current cash flow to forestall higher interest rate junior borrowing at the cost of reducing the likelihood of repaying senior debt.
} 
in the first period. When the pricing decisions of the competing firms are strategic complements, as is the case with linear demand, then considering future competition can slightly decrease the incentive to build a customer base. ${ }^{9}$ When firm $i$ lowers its price and gains a customer in the first it has the effect of taking away a fraction of a potential customer from $i$ 's competitors, decreasing the price they will charge, thus decreasing $i^{\prime} s$ future profits. On the other hand, there is an opposing effect; with an additional old customer in $t+1$, firm $i$ can commit to higher prices, which in turn leads the competitors to charge more. With a linear demand model, the first effect dominates, but is not very strong unless there are few firms and they are all very close competitors. ${ }^{10}$ Because obtaining a new customer tends to reduce the competitors' prices, the future value of a new customer tends to be a little less than the future margins from that customer. Considering competition in the future also has some effect on our analysis of mergers. The major effect is to push the price increase from the loss of competition into the future, while diminishing any immediate price increase. Because a merger tends to increase future prices, this increases the future value of new customers, and has the same effect as a decrease in the cost of serving new customers. ${ }^{11}$ This has the effect of diminishing the immediate price increase.

However, if the financial distress is seen as resulting from a transitory crises, than the financial efficiencies may be transitory too. Thus a merger during a financial crises might lead to an immediate price decrease due to alleviation of financial distress at the cost of a future price increase. Whether it is desirable to permit or block a merger

\footnotetext{
${ }^{9}$ Pricing decisions are said to be strategic complements if when one firm raises its price, it becomes more profitable for other firms to raise their price. Firms are said to be strategic substitutes if when one firm raises its price, it becomes more profitable for the other firms to lower their prices.

${ }^{10} \mathrm{It}$ is possible to quantify this using simulations. In a two period mode where there are the same number of new customers in both periods, if there are 4 equal firms, and the diversion ratios between any two firms was .25 , and the elasticity of old customers was about one third the elasticity of new customers, then $d \pi_{i 2} / d x_{i 1}$ would be about $95 \%$ of $\left(1-\zeta p_{i 2}\right)\left(p_{i 2}-c_{i 2}\right)$. The most extreme case would be if there were 2 firms, the diversion ratio was 1 , and old customers were completely inelastic, in this case $d \pi_{i 2} / d x_{i 1}$ would only be $1 / 3$ of $\left(1-\zeta p_{i 2}\right)\left(p_{i 2}-c_{i 2}\right)$.

${ }^{11}$ The anticipated future price increase is seen as a cost increase as long as new customers are myopic and do not consider future prices of the locked in good when they are making their purchasing decision. If they fully consider the future price increase in a rational manner, then an anticipated increase in the future price is seen as an increase in the current price. In either case, the fact that the merger tends to raise future prices tends to decrease the rise in the current price.
} 
may depend on the tradeoff between future price increases and current price increases.

It is often recognized that the competitive effects of a merger tend to fade over time, as the competitive environment tends to revert to a long term equilibrium. There are some reasons why policy makers should be more concerned with price increases and output reductions during crises then during times of economic stability and full employment. Due to sticky prices and other frictions it is quite likely that in times of crises, inputs (especially labor) might be priced above their social cost. Thus output restrictions might create dual deadweight losses, the total loss would include not only the difference between the consumers' willingness to pay and the firm's cost of production, but also the difference between the firm's cost of production and the actual social opportunity costs of the input.

One further complication behind a model of future competition is that any judgement of the welfare effects using a such model will depend strongly upon what happens when a firm fails. Much of these consequences have been discussed extensively in the literature on the failing firm defense(e.g., McFarland and Nelson (2008)), but there are some special considerations when switching costs are important. One could imagine that if a firm fails, it leaves the market completely. In this case, the impact of a firm failure on consumer welfare is likely to be much more severe than the effects of the merger. If the firm leaves the market completely, then all remaining firms are likely to increase their prices. The new customers who would have preferred the old firms good are forced to purchase goods they desire less and perhaps most importantly, the old customers are forced to pay switching costs or stop consuming altogether.

Another possibility is that the failed firm's assets and goodwill are purchased by one of the surviving firms in the industry. In that case, the failure of the firm has the same impact on future prices as the merger, but does not generate the 'financial efficiency' from alleviating financial distress that results from a voluntary merger. Furthermore the merger occurs only in the cases where the firm fails, so any expectation of future price increase that is conditional on the failure does not result in lower costs to the firm.

A final possibility is that if the firm fails, its productive assets and goodwill are 
sold to a new entrant. In that case, the major effect of the failure is financial, so consumers are not hurt by failures. Of course the direct effects of firm failure on competition is a topic that has been considered before, and understanding of these possible effects is the foundation for the failing firm defense. The contribution of this work is the construction of a framework to consider the effects of distress, rather than failure. For that reason, we believe it is preferable as a baseline for our analysis to consider the scenario where firm failure is purely financial and the assets of a firm that failed remain in the market as a new firm.

\subsection{Future Competition and Endogenous Failure}

In a model where the survival of one firm affects the future profits of another firm, endogenizing firm failure introduces some complicated strategic effects. To wit, if a firm is likely to achieve higher profits in the second period if their competitor fails, and the firm can make this failure more likely by charging lower prices and reducing their competitor's cash flow in the first period, this will encourage the firm to lower prices in the first period. We note again that the incentive to do so depends upon what happens to the firm that fails. If the impact of failure is purely financial, and all the manufacturing capacity and customer goodwill of the failed firm, is merely sold to a new competitor, the extant firms will receive no benefit from a firm failure. If the firm's assets are liquidated, and used outside of the industry, on the other hand, the surviving firms will receive a benefit when the firm fails. Finally, there is a scenario where the firms could actually be hurt by their competitors failure, if the manufacturing assets of the failed firm are transferred to a new firm, but this new firm does not command the goodwill and loyalty of the failed firms old customers, the new firm will have to compete aggressively to establish a customer base.

In any case, the incentive to underprice so as to drive competitors out of business is likely to be fairly small unless there are very few firms (i.e., 2 or 3 ) and the firms are very close competitors. For one, if the firms are not very close competitors, the

increment to the competitor's profit when firm $i$ fails is likely to be small compared to the increment to firm $i^{\prime} s$ profit when $i$ itself fails. Secondly if the firms are not close 
competitors, any action by a competitor is likely to have much more impact on that competitor than the firm in distress. If competing firms have an incentive to price more aggressively in response to a firm in distress, that does it make it less likely that a merger which alleviates distress will have the immediate effect of lowering prices, because the alleviation of financial distress diminishes the competitor's incentive to drive the firm out of business. On the other hand, the fact that competitors seek to drive the firm out of business implies that the firm's failure is likely to lead to a permanent exit of the firm's resources from the market, so that a merger which reduces the likelihood of firm failure is likely to have beneficial long term effects on consumer welfare.

\section{Conclusion}

In this paper we have illustrated one way in which imperfections in financial markets impact the welfare calculus of mergers. We have shown that when firms have some ability to lock in customers, financial distress might push firms to raise prices to focus on current profits.Financial distress decreases the value of future profits by decreasing the likelihood they are realized, and by making the eventual realization of those profits contingent on current cash flow, financial distress increases the importance of immediate revenue. When a merger alleviates financial distress, it increases the firm's incentive to keep prices low to build up a customer base, and even without any technological efficiencies from the merger, this might cause the merger to lower prices overall. Although in our model, switching costs are explicit and substantial, the general lessons from the model applies to any industry where increasing prices tends to increase current profits at the cost of future profits.

Of course, one might ask why a firm might be able to obtain financing through a merger with a competitor but not be able to attract financing from any other source, such as a merger outside of the industry, or a bank loan or stock offering. Of course this is a critique that also applies to the failing firm defense. We note that the financial distress we speak of is particularly likely to occur during a system wide liquidity crises. 
Under these circumstances asymmetric information is likely to present a substantial obstacle to deal-making if the prospective investors are uncertain about their ability to accurately assess the prospects of the distressed firms. A firm in the same industry is likely to be much more confident in their ability to assess the value of the target firm. Secondly, there may be substantial issues with monitoring, particularly if the target firm is near the zone of insolvency, when there is likely to be the most conflict of interest between equity and debt, and management and equity. An acquiring firm in the same industry is likely to have its own industry knowledge and be more able to cheaply monitor the target firm. Finally, a firm in the same industry is most likely to be able to benefit from synergies or other strategic factors.

With this paper, we wish call attention to the question of how competition policy should take financial factors into account. Our analysis abstracts from more macroeconomic public interest considerations, such as those invoked in recent mergers to save financial institution whose failure would have created the risk of a dangerous ripple effect on the financial system. ${ }^{12}$ It would be interesting to analyze the role of competition policy in lessening business cycle fluctuations. Political pressures could be applied to competition authorities to loosen enforcement so as prevent job losses or plant closures. ${ }^{13}$ What is the risk that business interests exert undue influence on competition standards? What are the competition distorting effects of government aid aimed at lessening the effect of a crisis? These and other interesting questions remain open for future research.

\section{$9 \quad$ References}

Asplund, Marcus, Rickard Eriksson, and Niklas Strand. 2005. "Prices, Margins and Liquidity Constraints: Swedish Newspapers, 1990-1992." Economica, 72(286),

\footnotetext{
${ }^{12}$ Despite widespread concerns about potential anti-competitive effects in the Scottish banking market, on October 31, 2008 the UK Secretary of State decided to overrule the advice of the Office of Fair Trading to refer Lloyds TSB's takeover of HBOS to the Competition Commission to protect the public interest in maintaining the financial stability in the country. See http://www.oft.gov.uk/shared_oft/press_release_attachments/LLloydstsb.pdf.

${ }^{13}$ See Cole and Ohanian's (2004) account of the $\bar{N}$ ew Deal policies following the Great Depression.
} 
$349-359$.

Banal-Estanol, Albert, and Marco Ottaviani. 2006. "Mergers with Product Market Risk." Journal of Economics \&6 Management Strategy, 15(3), 577-608.

Bagwell, Kyle, and Robert W. Staiger. 1997. "Collusion over the Business Cycle." Rand Journal of Economics, 28(1), 82-106.

Bolton, Patrick, and David S. Scharfstein. 1990. "A Theory of Predation Based on Agency Problems in Financial Contracting." American Economic Review, 80(1), 93-106.

Brander, James A. and Tracy R. Lewis. 1986. "Oligopoly and Financial Structure: The Limited Liability Effect." American Economic Review, 76(5), 956-970.

Busse, Meghan. 2002. "Firm Financial Condition and Airline Price Wars." Rand Journal of Economics, 33(2), 298-318.

Chevalier, Judith, and David Scharfstein. 1996. "Capital Market Imperfections and Countercyclical Markups: Theory and Evidence." American Economic Review, $86(4), 703-725$.

Cole, Harold L., and Lee E. Ohanian. 2004. "New Deal Policies and the Persistence of the Great Depression: A General Equilibrium Analysis." Journal of Political Economy, 112(4), 779-816.

Dasgupta, Sudipto, and Sheridan Titman. 1998. "Pricing Strategy and Financial Policy." Review of Financial Studies, 11(4), 705-737.

Farrell, Joseph and Carl Shapiro, 1990. "Horizontal Mergers: An Equilibrium Analysis." American Economic Review, 80(1), 107-126.

Klemperer, Paul. 1987. "Markets with Consumer Switching Costs." Quarterly Journal of Economics, 102(2), 375-394. 
Klemperer, Paul. 1995. "Competition When Consumers Have Switching Costs: An Overview with Applications to Industrial Organization, Macroeconomics, and International Trade." Review of Economic Studies, 62(4), 515-539.

Gottfries, Nils. 1991. "Customer Markets, Credit Market Imperfections and Real Price Rigidity." Economica, 58(231), 317-323.

McFarland, Henry, and Philip Nelson. 2008. "Failing Firms and Declining Industry." Chapter 69 in: Issues in Contemporary Law and Policy.

Perotti, Enrico C., and Javier Suarez. 2002. "Last Bank Standing: What I Gain if You Fail?" European Economic Review, 46(9), 1599-1622.

Rotemberg, Julio J., and Garth Saloner. 1996. "A Supergame-Theoretic Model of Price Wars during Booms." American Economic Review, 76(3), 390-407.

Showalter, Dean M. 1995. "Oligopoly and Financial Structure: Comment." American Economic Review, 85(3), 647-653.

Werden, Gregory J. 1996. "A Robust Test for Consumer Welfare Enhancing Mergers Among Sellers of Differentiated Products." Journal of Industrial Economics, 44(4), 409-413.

Williamson, Oliver E. 1968. "Economies as an Antitrust Defense: The Welfare Tradeoffs." American Economic Review, 58(1), 18-36. 